\title{
Drugs, Sex, Gender-Based Violence, and the Intersection of the HIV/AIDS Epidemic with Vulnerable Women in South Africa
}

\author{
Wendee M. Wechsberg, PhD, Charles D.H. Parry, PhD, and \\ Rachel K. Jewkes, MBBS, MSc, MD
}

\section{Summary}

Recent innovative research has identified key factors that put vulnerable South African women at risk of HIV/AIDS and gender-based violence, including highrisk patterns of alcohol abuse and sexual partnering, gender norms that place men in control in sexual relationships, low educational levels and limited access to employment, poor health care, inadequate housing, and sex work.

These studies suggest that targeted HIV-prevention interventions can effect improvement for this vulnerable population when programs

- remain sensitive to gender and cultural differences and expectations, and

- address the social and economic inequalities that make women vulnerable.

Solving these problems on a larger economic scale will require institutional participation and political support for women's equity, HIV-prevention literacy, and a broader HIV-prevention agenda.

This can be accomplished with a multilevel, collaborative response from government, community, and international partners using multiple prevention strategies and fostering sustainability.
Sub-Saharan Africa is the global epicenter of the HIV/ AIDS epidemic, accounting for more than two-thirds of recent HIV infections worldwide. ${ }^{1}$ In South Africa, with a population of 49 million, an estimated 5.2 million people live with HIV; ${ }^{2} 350,000$ people died of AIDS in 2007. ${ }^{3}$ Among all demographic groups, a greater burden of the disease falls to individuals who are disadvantaged, underserved, and vulnerable. This pattern is especially true for women. For example, HIV prevalence among women aged 25 to 29 is currently $33 \%{ }^{2}$ Young women aged 15 to 19 face particularly high risk, with prevalence 2.7 times higher than that of their male peers. In addition, HIV disproportionately affects specific racial groups, notably Black Africans. ${ }^{\star, 2}$

The HIV epidemic among women is fueled by endemic poverty; gender inequality and violence; widespread substance abuse; social norms that involve multiple, concurrent partnerships; and marked age differences between young women and their male partners. ${ }^{4-6}$ Within this context, many women resort to sex work for survival.

Among sex workers, alcohol and other drug use is particularly widespread because it helps to ameliorate the shame of conducting sex work and gives women the courage to talk with men for "dates." Although drug use-including alcohol, crack cocaine, and methamphetamine-may lower inhibitions for sexual

* The term Black conveys meanings unique to South Africa. During Apartheid, the government defined the population in terms of four racial categories under the law: Black, White, Coloured, and Indian. Coloured persons refers to those of mixed ancestry. Black refers to African people of Bantu ancestry. 
transactions, it increases the likelihood of high-risk sexual behaviors, such as nonuse or improper use of condoms. In addition, drug use may prevent women from negotiating risk reduction and remaining alert, and consequently from reducing physical and sexual violence. Overall, these women lack skills essential to reducing their chances of being victimized. The highly variable quality of public health services, limited access to mental health services, and very limited formal substance abuse treatment services for South African women compound the problem.

This policy brief examines the factors that increase women's risk for HIV/AIDS, highlights recent successful and innovative efforts to assess risk and prevent the spread of HIV/AIDS among this vulnerable population, and recommends multilevel policy actions.

\section{Factors That Increase South African Women's Risk for HIV/AIDS}

Several critical cultural and contextual factors affect risk:

- Apartheid destroyed pre-colonial models of family life, entrenched migrant labor, and promoted a cultural context in which high levels of drinking are often the norm. These effects have led to an increase in high-risk patterns of alcohol abuse and sexual partnering. ${ }^{8}$
- Gender norms place men in control in sexual relationships, allowing them to determine the circumstances and frequency of sex, dictating when or whether condoms are used, and legitimizing the use of sexual and physical violence against women. Social norms also favor multiple, concurrent sex partners and age-disparate sexual partnering. ${ }^{4,8,9}$

- Low educational levels for disadvantaged segments of the population have resulted in limited access to employment, health care, and proper housing, particularly for women; consequently, many poor women depend on men for economic support. ${ }^{8,10}$

- Many poor women resort to sex work and transactional sex for cash, food, clothing, shelter, and other provisions for their families. ${ }^{4,11}$

\section{Recent Innovative Research to Assess Risk and Prevent HIV/AIDS in South Africa}

Between 2001 and 2008, five innovative research projects were funded by the US National Institutes of Health and the Centers for Disease Control and Prevention to study vulnerable populations of South African women, including female drug users in Pretoria and Cape Town; female sex workers in Cape Town, Durban, and Pretoria; young rural women in the Eastern Cape; and drug-using girls out of school in Cape Town (Table 1).

\section{Table 1. Recent Studies to Assess Risk and Prevent HIV/AIDS in South Africa}

\begin{tabular}{|c|c|c|}
\hline Study & Description & Key Findings and Implications \\
\hline $\begin{array}{l}\text { The Women's Health } \\
\text { CoOp in the Western } \\
\text { Cape } \\
\text { (2004-2006; Wendee } \\
\text { M. Wechsberg, PhD, } \\
\text { Principal Investigator) }\end{array}$ & $\begin{array}{l}\text { This small randomized trial-sponsored by } \\
\text { NIDA and RTI, in collaboration with the Medical } \\
\text { Research Council of South Africa-examined } \\
\text { the relative feasibility of a woman-focused } \\
\text { intervention for high-risk behaviors in either a } \\
\text { group or an individual format and examined } \\
\text { the differences between Black and Coloured } \\
\text { women across pre- and post-intervention } \\
\text { measures with regard to alcohol and illicit drug } \\
\text { use and sex risk behaviors. }\end{array}$ & $\begin{array}{l}\text { Key findings were as follows: } \\
\text { - Women reduced drug use, increased male condom use, and reduced } \\
\text { physical and sexual abuse. } \\
\text { - Both the group and individual interventions facilitated a reduction in } \\
\text { risk behaviors, indicating that group interventions may be the more } \\
\text { cost-effective option. } \\
\text { - These findings helped to establish a larger women's project in the } \\
\text { region and begin the larger effectiveness study. }\end{array}$ \\
\hline
\end{tabular}


Table 1. Recent Studies to Assess Risk and Prevent HIV/AIDS in South Africa (continued)

\section{Study}

Rapid Assessment,

Response, and

Evaluation of Drug-

Using Sex Workers in

Durban, Cape Town, and

Pretoria

(2005-2008; Charles

Parry, PhD, Principal

Investigator)

\section{Description}

Funded by the US President's Emergency Fund for AIDS Relief (PEPFAR) through the Centers for Disease Control and Prevention, this study began with a rapid ethnographic assessment to learn more about patterns of drug use and HIV risk behaviors among drug-using, street-based sex workers in selected "hot spots" in three cities. ${ }^{12}$ This effort prepared for an intervention phase involving (1) the training of nongovernmental organizations (NGOs) engaged in community-based outreach and risk-reduction counseling with sex workers and (2) implementation strategies to better integrate drug treatment, HIV intervention, and other services to ensure that HIV-positive and HIV-negative clients would be linked to appropriate prevention, care, and treatment.

\section{Key Findings and Implications}

Key findings were as follows:

- Drugs play an organizing role in patterns of daily activities, with sex work being closely linked to buying, selling, and using drugs.

- The activities of female sex workers are subject to considerable control by individual pimps, many of whom also function as landlords and drug dealers.

- The intervention work to date in Durban has

- revealed a willingness by NGOs to expand staff skills and broaden outreach and service-delivery activities to address both sexual and drug-related HIV risk in vulnerable populations;

- demonstrated increasing uptake of voluntary counseling and testing (VCT) and other services; and

- improved the integration of drug treatment, HIV intervention, and other services through strengthened referrals

Outreach and VCT targeting sex workers should be made more accessible in areas with high levels of sex work and should be sensitive to issues of stigma. Prevention campaigns aimed at drug-using sex workers should focus not only on HIV risk behavior, but also on access to drug treatment and HIV services.

\begin{tabular}{ll}
\hline $\begin{array}{l}\text { Impact of Stepping } \\
\text { Stones on Sexual } \\
\text { Behavior in Rural South } \\
\text { Africa }\end{array}$ & $\begin{array}{l}\text { A cluster RCT funded by the National Institute } \\
\text { of Mental Health, this study evaluated the } \\
\text { impact of the community-based HIV prevention } \\
\text { (2002-2006; Rachel } \\
\text { Jewkes, MBBS, MSc, MD, }\end{array}$ \\
$\begin{array}{l}\text { intervention Stepping Stones on the sexual } \\
\text { Principalth of rural South African youth. This } \\
\text { participatory program worked to improve }\end{array}$ \\
$\begin{array}{l}\text { sexual health by building stronger, more } \\
\text { gender-equitable relationships. In addition, it } \\
\text { sought to increase understanding of the impact } \\
\text { of a gender-transformative intervention on HIV } \\
\text { and HSV-2 seroincidence. }\end{array}$ \\
\hline
\end{tabular}

Examination of Methamphetamine Use and Sexual Behavior in Cape Town

(2006; Wendee M.

Wechsberg, PhD, Principal Investigator)
This study, funded by NIDA, investigated the link between methamphetamine (and other drug) use and sexual risk behavior among young (out-of-school) 13- to 20-year-old females in poor communities in Cape Town. A quantitative study of 450 girls and young women in 10 suburbs known to have high levels of drug use preceded a qualitative component to examine issues related to drug use, violence, and sexual risk behavior in greater depth by using focus groups with 37 of the young women who had participated in the quantitative survey. Black African females were compared with Coloured females.
Key findings were as follows:

- Stepping Stones effectively changed men's gender-related behavior, with a significant reduction in perpetration of intimate-partner violence sustained 2 years after the intervention -and a reduction in transactional sex and problem drinking.

- The intervention led to a $33 \%$ reduction in HSV-2 incidence for men and women. This result showed that sexual behaviors changed, but the study did not establish which behaviors of women had changed.

- Intervening with male partners in rural parts of South Africa is essential for comprehensive HIV prevention in women.

Key findings were as follows:

- $62 \%$ of females reported use of crystal methamphetamine (locally called tik).

- Coloured teens reported involvement with gangs and the greatest use of tik.

- Most teens who had ever used tik used it every day and reported trading sex for it.

- Black African teens were sexually active before age 15 and reported sexually transmitted infections.

- The two groups resembled each other in reporting little use of condoms.

- The high rate of drug use among teens appeared to be related to an $88 \%$ unemployment rate and boredom.

The high prevalence of tik use among young, out-of-school, unemployed women leads to many other risk behaviors. The need exists for interventions to address risk and for treatment programs sensitive to issues surrounding gender, age, and culture. 


\section{Implications for Policy Makers}

The findings from these important studies have identified the factors that put these vulnerable women at risk for HIV/AIDS and gender-based violence. The results suggest that targeted HIV-prevention intervention programs can effect improvements for this vulnerable population when the programs remain sensitive to gender and cultural differences and expectations, and when they address the social and economic inequalities that make women vulnerable.

Together these findings have important implications for public policy because solving these problems on a larger economic scale will require institutional participation and political support for women's equity, HIV-prevention literacy, and a broader HIV-prevention agenda. This goal can be accomplished with a multilevel, collaborative response from government, community, and international partners using multiple prevention strategies and fostering sustainability (Table 2).

\section{References}

1. Joint United Nations Programme on HIV/AIDS (UNAIDS); World Health Organization (WHO). AIDS epidemic update 2009. Available from: http://data.unaids. org/pub/Report/2009/JC1700_Epi_Update_2009_en.pdf.

2. Shisana O, Rehle T, Simbayi LC, Zuma K, Jooste S, Pillayvan-Wyk V, et al. South African National HIV Prevalence, Incidence, Behaviour and Communication Survey 2008: a turning tide among teenagers? Cape Town: HSRC Press; 2009.

3. Joint United Nations Programme on HIV/AIDS (UNAIDS); World Health Organization (WHO). SubSaharan Africa AIDS epidemic: update regional summary. Geneva: UNAIDS, WHO; 2008.

4. Dunkle KL, Jewkes RK, Brown HC, Gray GE, Mclntryre JA, Harlow SD. Gender-based violence, relationship power, and risk of HIV infection in women attending antenatal clinics in South Africa. Lancet. 2004;363(9419):1415-21.

5. Jewkes R, Dunkle K, Nduna M, Jama N. Partner violence and relationship gender power inequity increase risk of incident HIV infections in a cohort of young South African women. Lancet. In press.
Table 2. Summary of Key Recommendations for Policy and Practice

\section{Policy Level Recommendation}

Government - National strategies should be developed and policies should be adopted to effectively reduce the intersecting problems of gender inequality, substance abuse, violence against women, and HIV. Political leadership at the highest level is required to achieve this task.

- The government should scale up and implement best-evidence interventions that help women and men empower themselves to protect against HIV. These interventions should aim to transform gender-inequitable attitudes and practices, especially as related to the intersecting behaviors of substance use, sexual risk, and violence against women. ${ }^{13,14}$

- The government should involve health providers in developing ways to better reach and treat women with alcohol and other drug problems and to increase providers' awareness of woman-centered intervention strategies, such as screening, brief interventions, and referral to treatment. In doing so, the government should ensure that a broad range of services are better marketed to vulnerable women and that such services do not stigmatize women who engage in sex work or who use drugs.

Community - Programs are needed to keep adolescent girls in school in order to decrease the high dropout rates and prevent substance use that leads to early pregnancy, disease, and victimization. ${ }^{15}$

- Community-based activities should challenge gender inequity and the cultural acceptability of gender-based violence.

- Community-level organizational networks should translate research into practice through ongoing evidence-based interventions to reduce vulnerable populations' risk of violence and other healthrelated harms.

- Community efforts should support evidencebased intervention programs that will also mentor and develop individuals to serve as community role models for both genders in a transformation of sexual responsibility and communication.

International - International partners should increase research Partners on interventions that help women to empower themselves and to assess the sustainability and scalability of best practices.

- International partners should provide resources adequate to enhance the structures of the national, regional, and global AIDS architecture and should involve women's rights groups and organizations to more effectively address the gender-related dimensions of HIV/AIDS in South Africa. 
6. Jewkes R, Dunkle K, Nduna M, Levin J, Jama N, Khuzwayo N, et al. Factors associated with HIV serostatus in young rural South African women: connections between intimate partner violence and HIV. Int J Epidemiology. 2006;35(6):1461-8.

7. Wechsberg WM, Luseno WK, Lam WK. Violence against substance-abusing South African sex workers: intersection with culture and HIV risk. AIDS Care. 2005;17:S55-S64.

8. Coovadia H, Jewkes R, Barron P, Sanders D, McIntyre D. The health and health system of South Africa: historical roots of current public health challenges. Lancet. 2009;374(9692):817-34.

9. Sawyer-Kurian KM, Wechsberg WM, Luseno WK. Substance abuse, violence against women, and HIV risks: men's voices from Cape Town, South Africa. Psychol Men \& Masculinity. 2009;10:13-29.

10. Wechsberg WM, Luseno WK, Riehman K, Karg R, Browne F, Parry C. Substance use and sexual risk within the context of gender inequality in South Africa. Subst Use Misuse. 2008;43:1186-201.
11. Wechsberg WM, Luseno WK, Lam WK, Parry CDH, Morojele NK. Substance use, sexual risk, and violence: HIV prevention intervention with sex workers in Pretoria. AIDS Behav. 2006;10(2):131-7.

12. Parry CDH, Dewing S, Petersen P, Carney T, Needle R, Kroeger K, et al. Rapid assessment of HIV risk behavior in drug using sex workers in three cities in South Africa. AIDS and Behavior. 2009;13:849-59.

13. Jewkes R, Nduna M, Levin J, Jama N, Dunkle K, Puren A, et al. Impact of Stepping Stones on HIV, HSV-2 and sexual behaviour in rural South Africa: cluster randomised controlled trial. Br Med J. 2008;337(71):a506.

14. Wechsberg WM, Luseno WK, Kline TL, Browne FA, Zule WA. Preliminary findings of an adapted evidence-based woman-focused HIV intervention on condom use and negotiation among at-risk momen in Pretoria, South Africa. J Prev Interv Community. 2010;38:132-46.

15. Wechsberg WM, Jones HE, Zule WA, Myers BJ, Browne FA, Kaufman MR, et al. Methamphetamine ("tik") use and its association with condom use among out-of-school females in Cape Town, South Africa. Am J Drug Alcohol Abuse. In press.

\section{About the Authors}

Wendee M. Wechsberg, $\mathrm{PhD}$, is senior director of the Substance Abuse Treatment Evaluations and Interventions Research Program at RTI International.

Charles D.H. Parry, PhD, is director of the Alcohol \& Drug Abuse Research Unit at the South African Medical Research Council, Cape Town, South Africa.

Rachel K. Jewkes, MBBS, MSc, MD, is director of the Gender \& Health Research Unit at the South African Medical Research Council, Cape Town, South Africa.
RTI Press Research Briefs and Policy Briefs are scholarly essays on policy, methods, or other topics relevant to RTI areas of research or technical focus. RTI International 3040 Cornwallis Road, PO Box 12194 Research Triangle Park, NC 27709-2194 USA

Tel: $\quad 919.541 .6000 \quad$ Fax: 919.541 .5985

E-mail: rtipress@rti.org Web site: www.rti.org

(C)2010 Research Triangle Institute. RTI International is a trade name of Research Triangle Institute.

All rights reserved. Please note that this document is copyrighted and credit must be provided to the authors and source of the document when you quote from it. You must not sell the document or make a profit from reproducing it.

RTI Press publication PB-0001-1005 doi:10.3768/rtipress.2010.PB.0001.1005

www.rti.org/rtipress 